Departamento de Ciência e Tecnologia, Secretaria de Ciência, Tecnologia e Insumos Estratégicos, Ministério da Saúde

Correspondência | Correspondence:

Decit - Departamento de Ciência e Tecnologia

do Ministério da Saúde

Esplanada dos Ministérios

Bloco G sala 845

70058-900 Brasília, DF, Brasil

Texto de difusão técnico-científica do

Ministério de Saúde.

\section{Fomento às pesquisas em terapia celular e células- tronco no Brasil}

\section{Cell therapy and stem cells research funding in Brazil}

O Ministério da Saúde, por intermédio do Departamento de Ciência e Tecnologia (Decit) da Secretaria de Ciência, Tecnologia e Insumos Estratégicos (SCTIE), vem apoiando atividades de pesquisa científica, tecnológica e de inovação no campo da terapia celular e células-tronco no Brasil em áreas definidas como prioritárias pela Política Nacional de Saúde desde 2004. A estratégia visa induzir a geração de novos conhecimentos e o desenvolvimento de produtos e processos biotecnológicos com potencial de aplicação na área da saúde humana. O desenvolvimento dessas pesquisas teve, desde o início, outros alicerces governamentais fundamentais: o Ministério de Ciência e Tecnologia, por intermédio do Conselho Nacional de Desenvolvimento Científico e Tecnológico (CNPq) e da Financiadora de Estudos e Projetos (Finep); e do Ministério da Educação, por intermédio da Coordenação de Aperfeiçoamento de Pessoal de Nível Superior (Capes).

\section{Instituto do Milênio de Bioengenharia Tecidual}

A pesquisa com terapia celular e células-tronco começou a se desenvolver no Brasil em 2002 a partir de uma iniciativa do Ministério da Ciência e Tecnologia, que, por intermédio do $\mathrm{CNPq}$, criou os Institutos do Milênio, um programa virtual com vista a fomentar pesquisas de excelência em áreas estratégicas para o desenvolvimento do País.

Naquele ano, propôs-se a criação de um Instituto do Milênio de Bioengenharia Tecidual (IMBT) com o objetivo de capacitar o Brasil - científica e tecnologicamente - para introduzir e desenvolver uma nova área de conhecimento médico, a medicina regenerativa, visando ao desenvolvimento de novas abordagens terapêuticas utilizando terapia celular para o reparo de órgãos e tecidos lesados. Com a sua aprovação, diversos grupos de pesquisa de diferentes instituições brasileiras, como a Fundação Oswaldo Cruz (Fiocruz) e os três institutos nacionais do Ministério da Saúde (Instituto Nacional de Cardiologia - INC, Instituto Nacional de Câncer-Inca e Instituto Nacional de Traumatologia e Ortopedia - Into), além de universidades públicas, hospitais públicos e privados, passaram a concentrar esforços para desenvolver a temática da medicina regenerativa no País. As áreas de concentração dos pesquisadores associados ao IMBT eram os biomateriais, as células-tronco e suas aplicações terapêuticas em modelos pré-clínicos, com possível translação para a clínica.

Durante os três anos de vigência do IMBT, esse grupo pioneiro alcançou avanços promissores, chegando-se num curto intervalo de tempo da bancada à clínica. Esse esforço foi fundamental, sobretudo quando o novo edital dos Institutos do Milênio não aprovou a renovação do IMBT e o Ministério da Saúde garantiu a continuidade do projeto.

\section{Estudo Multicêntrico Randomizado de Terapia Celular em Cardiopatias}

As pesquisas pré-clínicas e clínicas desenvolvidas durante a vigência do IMBT resultaram em um promissor avanço da terapia celular para doenças cardíacas. A comunidade científica já tinha acumulado dados suficientes para mostrar que a terapia celular usando células mononucleares derivadas da medula óssea do próprio paciente era exeqüível. Entretanto, tornava-se necessário avançar com as pesquisas clínicas para os ensaios de fase 3, os quais demandavam estudos multicêntricos, randomizados, placebo-controlados e duplo-cegos. Para comprovar a eficácia e a segurança do implante autólogo de células de medula óssea, o Ministério da Saúde lançou em 2004, em parceria com a Finep, uma chamada pública para fomentar um Estudo Multicêntrico Randomizado de Terapia Celular em Cardiopatias (EMRTCC). $\mathrm{O}$ edital contemplou estudos com pacientes com uma das seguintes cardiopatias: infarto agudo do miocárdio, 
doença isquêmica crônica do coração, cardiomiopatia dilatada e cardiomiopatia chagásica.

O EMRTCC conta com a participação de um centro coordenador, quatro centros-âncora e um grande número de centros colaboradores localizados em diversos pontos do País. A coordenação nacional do EMRTCC está a cargo do Instituto Nacional de Cardiologia, unidade pública federal de referência para o tratamento de cardiopatias. Os centros-âncora selecionados são instituições que apresentam serviço de cardiologia instituído e infra-estrutura de pesquisa na área, além de histórico de liderança em pesquisa clínica e terapia celular. São eles o Hospital Pró-Cardíaco no Rio de Janeiro e a Universidade Federal do Rio de Janeiro (infarto agudo do miocárdio), o Instituto do Coração da Universidade de São Paulo (doença isquêmica crônica do coração), o Instituto Nacional de Cardiologia no Rio de Janeiro (cardiomiopatia dilatada) e o Hospital Santa Izabel e o Centro de Pesquisas Gonçalo Muniz da Fiocruz, ambos na Bahia (cardiomiopatia chagásica). Os centros colaboradores, por sua vez, são hospitais que dispõem de serviço de cardiologia instituído e estão capacitados a fornecer pacientes corretamente diagnosticados e garantir seu seguimento durante o estudo.

O EMRTCC, ainda em desenvolvimento, representa a maior alocação de recursos já feita no País para um projeto de pesquisa clínica, alcançando o volume total de mais de R\$ 13 milhões. Representa, também, o maior estudo de terapia celular em cardiopatias financiado no mundo, tanto pelo número de pacientes (1.200) quanto pelo número de instituições envolvidas no projeto (66), estendendo-se do Amazonas ao Rio Grande do Sul. Esse cenário colocou o Brasil em posição de destaque no mapa da terapia celular e células-tronco mundial. Espera-se, ao final de seis e doze meses de tratamento com células mononucleares de medula óssea, que haja um aumento médio de 5\% na fração de ejeção do ventrículo esquerdo em relação ao grupo controle.

O segmento de cardiomiopatia chagásica já encerrou o recrutamento de pacientes e terá seus resultados divulgados, ainda este ano, no European Society of Cardiology Congress, a realizar-se em Estocolmo. O segmento de cardiomiopatia dilatada encerrará o recrutamento de pacientes em julho do ano corrente e os resultados preliminares deverão ser divulgados no American Heart Association Scientific Sessions, a ser realizado em novembro deste ano, em Chicago. Já o segmento de doença isquêmica crônica do coração ainda está recrutando pacientes e tem previsão para conclusão até o final deste ano. Outro estudo é o segmento de infarto agudo do miocárdio, que também continua recrutando pacientes, sendo prevista uma análise interina dos resultados para o final do ano.
Protocolos de pesquisa, relatos de caso, termos de consentimento, procedimentos operacionais padrão e formulários estão disponíveis no portal do Estudo Multicêntrico Randomizado de Terapia Celular em Cardiopatias. $^{\text {a }}$

\section{Primeiro Edital de Células-tronco}

Em 2005, o Ministério da Saúde, juntamente com o $\mathrm{CNPq}$, fomentou um edital de mais de R\$ 10 milhões com o objetivo de apoiar a formação e o fortalecimento de grupos de pesquisa que promovessem o desenvolvimento de procedimentos terapêuticos inovadores em terapia celular utilizando células-tronco.

Dentre os 45 projetos de pesquisa aprovados, foram desenvolvidas 11 (24\%) pesquisas clínicas, 13 (29\%) pesquisas pré-clínicas e 21 (47\%) pesquisas básicas. Quanto ao tipo celular, 87\% dos projetos utilizaram células-tronco adultas e 13\%, células-tronco embrionárias.

Apesar de constituírem uma minoria, merecem destaque as pesquisas com células-tronco embrionárias humanas. Com a aprovação da Lei de Biossegurança (Lei $\left.\mathrm{n}^{\mathrm{o}} 11.105 / 2005\right)$ pelo Congresso Nacional, em março de 2005, foi autorizada a utilização de célulastronco embrionárias obtidas de embriões humanos para fins de pesquisa, pondo fim a um largo período de incertezas aos desafios científicos e às restrições legais associados ao tema.

Os projetos financiados já foram finalizados e tiveram seus principais resultados avaliados, em 2007, durante uma reunião presencial com os pesquisadores agraciados pelo edital. $\mathrm{O}$ empenho dos pesquisadores culminou no desenvolvimento da primeira linhagem brasileira de células-tronco embrionárias humanas por um grupo de pesquisadores da Universidade de São Paulo. Outro avanço alcançado é o desenvolvimento da primeira linhagem brasileira de um novo tipo de célula-tronco pluripotente, as células-tronco pluripotentes induzidas (iPSC, do inglês induced pluripotent stem cell), obtidas por meio da manipulação genética de células-tronco adultas. Essa pesquisa foi coordenada pela equipe de pesquisadores da Universidade Federal do Rio de Janeiro e do Instituto Nacional de Câncer.

\section{Segundo Edital de Células-tronco}

Além das doenças cardíacas, o aumento progressivo das doenças crônico-degenerativas e traumáticas associado ao envelhecimento da população também impacta o Sistema Único de Saúde. Essas doenças são alvo de pesquisas pela comunidade científica brasileira ligada ao campo da terapia celular e células-tronco. Reco-

a Estudo Multicêntrico Randomizado de Terapia Celular em Cardiopatias [Internet] [citado 2010 jun 22] Disponível em: http://terapiacelular.hcl. gov.br/protocolos/cardiomiopatias.php 
nhecendo a qualidade dessas pesquisas e respondendo aos avanços alcançados na área, o Ministério da Saúde lançou em 2008, por meio do CNPq, um novo edital com o objetivo de financiar projetos de pesquisa básica, pré-clínica e clínica que visassem ao desenvolvimento de procedimentos terapêuticos inovadores em terapia celular utilizando células-tronco.

Esse edital, assim como o primeiro, foram lançados em um ano em que decisões legais críticas para o pleno desenvolvimento da área foram tomadas no Brasil. Apesar de a Lei de Biossegurança, de 2005, ter autorizado a utilização de células-tronco embrionárias obtidas de embriões humanos para fins de pesquisa, sua constitucionalidade foi contestada pelo então Procurador-geral da República em maio daquele mesmo ano. Ficou-se assim em um limbo jurídico que só veio a ser solucionado em 2008, quando o Supremo Tribunal Federal aprovou, sem restrições, a continuidade das pesquisas. O edital lançado em 2008, assim como o de 2005 , permitiam e estimulavam as pesquisas com células-tronco embrionárias humanas.

Foram contemplados nesse Edital 52 projetos de pesquisa (17 de pesquisa básica, 32 de pesquisa pré-clínica e três de pesquisa clínica) abordando o potencial terapêutico de células-tronco embrionárias, iPSC e/ou célulastronco adultas para doenças neurológicas, hepáticas, renais, pulmonares e auto-imunes, além de deficiências auditivas e visuais, lesões ósseas, musculares, de pele, medula e nervos periféricos, dentre outros. Esses projetos se encontram em fase de desenvolvimento, tendo-se investido, até o presente momento, um volume total de recursos de mais de $\mathrm{R} \$ 11$ milhões.

\section{Centros de Tecnologia Celular}

O ano de 2008 foi marcado por outra importante iniciativa do Ministério da Saúde que consolidava a pesquisa em terapia celular e células-tronco no Brasil: lançamento de uma chamada pública, em parceria com a Finep e o Banco Nacional de Desenvolvimento Econômico e Social (BNDES), com o objetivo de criar Centros de Tecnologia Celular (CTC) que pudessem produzir os mais diversos tipos de células-tronco humanas em condições de boas práticas de manufatura (BPM). Nesses CTC, prevê-se a produção tanto de células-tronco pluripotentes (embrionárias e iPSC) quanto multipotentes (adultas hematopoiéticas, mesenquimais, cardíacas e neurais).

Dessa forma, o Brasil se preparava para enfrentar os desafios da terapia celular com o uso de células-tronco, cujos processos de isolamento, purificação e cultivo demandam tecnologia de ponta e custo elevado. Assim, qualquer que fosse o tipo celular adequado para o tratamento de uma determinada doença que exigisse a terapia celular como alternativa terapêutica encontraria o País com infra-estrutura adequada já implantada para produzi-lo, eliminando assim a dependência de tecnologias desenvolvidas no exterior.

Oito instituições, localizadas em cinco estados brasileiros, foram selecionadas para constituir os CTC: o Núcleo de Terapia Celular e Molecular da Universidade de São Paulo (SP); a Universidade de São Paulo (SP); a Fundação Hemocentro de Ribeirão Preto (SP); o Instituto de Biociências da Universidade de São Paulo, em parceria com o Instituto de Ciências Biomédicas da Universidade Federal do Rio de Janeiro (SP/RJ); o Instituto Nacional de Cardiologia (RJ); o Monte Tabor/ Hospital São Rafael (BA); a Pontifícia Universidade Católica do Paraná (PR); e o Hospital de Clínicas de Porto Alegre (RS). Dois desses CTC já se encontram em funcionamento, um em Ribeirão Preto (SP) e outro em Salvador (BA). Os demais se encontram em fase de projeto ou em construção, com previsão para funcionamento ainda este ano ou apenas em 2011.

O montante de recursos investidos na instalação dos CTC alcança, até o presente momento, o valor total de $\mathrm{R}$ \$ 28 milhões.

\section{Rede Nacional de Terapia Celular}

O segundo edital de células-tronco e a chamada pública dos CTC, ambos lançados em 2008, consolidaram um financiamento ininterrupto para a área, que se iniciou em 2002 com o IMBT. Além dos recursos federais, é mister destacar a participação das agências estaduais de fomento à pesquisa, solidificando a pesquisa em terapia celular e células-tronco no País de tal modo que a organização de uma rede se tornou necessária.

Essa rede, chamada Rede Nacional de Terapia Celular (RNTC), surgiu como uma conseqüência natural do esforço nacional de pesquisa e do avanço contínuo no campo. A evolução da pesquisa em terapia celular no Brasil é corroborada pelo número de publicações de artigos científicos em revistas indexadas entre 2000 e 2008, que cresceu mais de 11 vezes: em 2009 foram mais de 220 publicações brasileiras relacionadas ao tema.

A RNTC é constituída pelos 52 grupos de pesquisa cujos projetos foram aprovados pelo segundo edital de células-tronco, lançado em 2008, e pelos oito CTC a serem implantados a partir da chamada pública também lançada nesse ano. Possui, ainda, um centro coordenador sediado no Instituto Nacional de Cardiologia. Além do papel já mencionado de desenvolver e aprimorar técnicas de produção de células-tronco humanas, os CTC também têm a função de dar apoio à qualificação de recursos humanos para a própria Rede e para o setor privado, além de gerar competência tecnológica na área para garantir a prestação de serviços e o fornecimento de células-tronco para os ensaios clínicos da Rede. Com esse desenho pioneiro, a RNTC configura uma iniciativa em termos de pesquisa científica e desenvolvimento tecnológico que é inédita no mundo. 
A RNTC possui uma página na internet ${ }^{\mathrm{b}}$ na qual os pesquisadores associados à Rede e os resumos dos projetos que estão sendo executados se encontram listados. A Rede disponibiliza um sistema de acesso comum aos dados produzidos pelas pesquisas desenvolvidas no País que envolvem terapia celular e, ao mesmo tempo, promove a integração dos grupos de pesquisa de todo o Brasil que atuam na área. Além disso, a Rede possibilita um trabalho colaborativo às instituições e facilita a troca de informações, acelerando a difusão do conhecimento entre a comunidade científica e incentivando o avanço tecnológico para continuar progredindo nos estudos da medicina regenerativa.

\section{Atividades de Cooperação Internacionais}

O Ministério da Saúde, por meio da RNTC, estabeleceu a criação do Programa Binacional de Terapia Celular, denominado Probitec Brasil/Argentina, um programa de trabalho conjunto com vista a intensificar a cooperação científica entre os dois países, apoiar atividades de pesquisa, desenvolvimento tecnológico e formação de pessoal qualificado desses países pelos próximos cinco anos. $\mathrm{O}$ acordo foi pactuado por representantes do Ministério da Saúde (SCTIE/Decit), Ministério da Ciência e Tecnologia (CNPq) e Ministério da Educação (Capes) do Brasil e do Ministério de Ciência, Tecnologia e Inovação Produtiva da Argentina durante o International Symposium on Stem Cell Research, realizado em Buenos Aires, em novembro de 2009.

Essa iniciativa se insere no marco da política Sul-Sul do Governo Federal, apoiando atividades de cooperação bem-sucedidas entre o Brasil, os países da África, os países da América Latina e a Índia, dentre outros.
Devem ser mencionadas, nesse âmbito, duas ações que mostram o impacto benéfico dessas atividades conjuntas no campo da formação de recursos humanos para a saúde pública: os programas de pós-graduação da Fiocruz em Maputo (Moçambique) e de Buenos Aires (Argentina), na estratégica "Administração Nacional de Laboratórios de Saúde". O apoio institucional a projetos de pesquisa binacionais na fronteira do conhecimento das terapias celulares e células-tronco serve também para aprofundar as atividades que os grupos de pesquisa de ambos os países vêm desenvolvendo e, ainda, para consolidar mais uma etapa de colaboração entre os dois governos.

\section{Perspectivas Futuras}

Apesar do entusiasmo dos pesquisadores e das esperanças depositadas por uma parcela considerável da população que poderá um dia beneficiar-se dos avanços alcançados na área da medicina regenerativa, ainda são necessárias muitas pesquisas e disposições políticas, éticas e morais para compor o cenário ideal ao pleno desenvolvimento dessa nova área terapêutica. O tratamento de doenças utilizando células-tronco ainda não é reconhecido como parte do arsenal terapêutico clinicamente comprovado e, em função disso, é considerado experimental pela comunidade científica em geral. Ressalta-se, portanto, que o uso de células-tronco para essa finalidade encontra-se, neste momento, restrito às pesquisas clínicas. Entretanto, espera-se que num futuro próximo as atividades de pesquisa no campo possam contribuir decisivamente para a transferência do conhecimento gerado e a incorporação das tecnologias desenvolvidas nos serviços de atenção à saúde e, conseqüentemente, na melhoria da qualidade de vida da população brasileira.

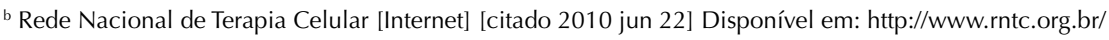

